\title{
Spinal Anesthesia for Urologic Surgery in an Infant With Palliated Single Ventricle Physiology
}

\author{
Alexander B. Froyshteter ${ }^{\mathrm{a}, \mathrm{d}}$, Emmett E. Whitaker ${ }^{\mathrm{a}, \mathrm{b}}$, Jason A. Bryant ${ }^{\mathrm{a}, \mathrm{b}}$, \\ Christina B. Ching ${ }^{\mathrm{c}}$, Joseph D. Tobias ${ }^{\mathrm{a}, \mathrm{b}}$
}

\begin{abstract}
Although commonly practiced in the adult population, spinal anesthesia has seen sporadic use in the pediatric population, being employed historically as a means of avoiding apnea following general anesthesia with halothane. With the emergence of evidence that specific anesthetic agents may affect future neurocognitive outcomes, there has been an increased focus on alternatives to general anesthesia, including spinal anesthesia. However, spinal anesthesia may also have applications in patients with co-morbid conditions that increase the risk of general anesthesia. We present the use of spinal anesthesia during urologic surgery in a 19-month-old boy with hypoplastic left heart syndrome who had undergone surgical palliation. The use of spinal anesthesia in patients with congenital heart disease is reviewed, potential hemodynamic consequences are presented, and the use of spinal anesthesia as an alternative to general anesthesia is discussed.
\end{abstract}

Keywords: Spinal anesthesia; Congenital heart disease; Hypoplastic left heart syndrome; Regional anesthesia

\section{Introduction}

Although commonly practiced in the adult population, the use of spinal anesthesia in infants and children remains limited. Spinal anesthesia initially gained popularity as it was shown to be a suitable alternative to general anesthesia in the highrisk, former preterm neonate [1-7]. In this population, spinal anesthesia was used instead of general anesthesia to limit the

Manuscript accepted for publication October 17, 2016

aDepartment of Anesthesiology \& Pain Medicine, Nationwide Children's Hospital, Columbus, OH, USA

${ }^{b}$ Department of Anesthesiology \& Pain Medicine, The Ohio State University College of Medicine, Columbus, OH, USA

'Department of Urology, Nationwide Children's Hospital and The Ohio State University College of Medicine, Columbus, OH, USA

${ }^{\mathrm{d} C}$ Corresponding Author: Alexander B. Froyshteter, Department of Anesthesiology \& Pain Medicine, Nationwide Children's Hospital, 700 Children's Drive, Columbus, OH 43205, USA.

Email: Alexander.Froyshteter@nationwidechildrens.org

doi: http://dx.doi.org/10.14740/jmc2673w incidence of postoperative complications, especially apnea and postoperative respiratory dysfunction, which was noted following general anesthesia with halothane. However, its use decreased as the risk of apnea was shown to be limited with the introduction of the new volatile anesthetic agents, sevoflurane and desflurane $[8,9]$. More recently, there has been renewed interest in the use of spinal anesthesia based on findings from animal models and retrospective cohort studies regarding the potential neurocognitive effects of general anesthesia during the neonatal period or infancy [10-14]. Despite the lack of prospective trials to clearly demonstrate such issues, spinal anesthesia has been reintroduced as a means of avoiding general anesthesia during the potentially vulnerable time period of central nervous system development. Additionally, in patients with significant co-morbid conditions, spinal anesthesia may offer a safety advantage over general anesthesia for brief $(<90 \mathrm{~min})$ surgical procedures. The authors report the use of spinal anesthesia during circumcision in a 19-month-old, 12.1 $\mathrm{kg}$ infant with hypoplastic left heart syndrome (HLHS) who had undergone hybrid palliation [15]. The applications of spinal anesthesia in high-risk patients with co-morbid congenital heart disease (CHD) are reviewed, techniques are described, and potential adverse hemodynamic and respiratory effects are discussed with emphasis on the patient with palliated HLHS.

\section{Case Report}

Institutional Review Board approval is not required at Nationwide Children's Hospital (Columbus, $\mathrm{OH}$ ) for the presentation of single case reports. The patient was a 19-month-old toddler (weight $12.1 \mathrm{~kg}$ ) with HLHS (aortic atresia and mitral stenosis type) who had completed the stage I hybrid procedure and a comprehensive stage II palliation, presenting for circumcision due to phimosis. Medications at the time of surgery included enalapril $1.5 \mathrm{mg}$ twice daily, digoxin $50 \mu \mathrm{g}$ twice daily, and aspirin $40.5 \mathrm{mg}$ daily. His aspirin was held for 7 days prior to the scheduled surgery. He had no known drug allergies and no new laboratory tests were performed prior to the procedure. Due to his extensive cardiac history and a history of the need for prolonged postoperative ventilation following his previous cardiac surgical procedures, the surgeon had a frank discussion with the family regarding the potential risks of this elective surgery and offered ongoing observation of the urologic condition. Despite this, the family still desired surgery. At this point, 
a discussion was held including the surgeon, anesthesiologist, and cardiologist regarding potential spinal anesthesia in an effort to avoid general anesthesia and airway instrumentation. The patient was deemed a suitable candidate, and the option was presented to the parents who consented to proceed with spinal anesthesia. On the morning of surgery, the patient was held nil per os (NPO) for $2 \mathrm{~h}$ for clear liquids and for $8 \mathrm{~h}$ for solids. The patient's vital signs were blood pressure 104/61 mm $\mathrm{Hg}$, heart rate 110 beats/min, respiratory rate 28 breaths/min, oxygen saturation $85 \%$ on room air, and temperature of 36.3 ${ }^{\circ} \mathrm{C}$. In the preoperative holding area, $\mathrm{LMX}^{\circledR}$ cream (4\% topical lidocaine, Ferndale Laboratories Inc., Ferndale, MI) was applied to the lumbar area to minimize discomfort with the placement of the spinal needle. The patient was transported to the operating room and standard American Society of Anesthesiologists' monitors were applied. He was positioned in a curled sitting position. Using aseptic technique, a $1.5 \mathrm{inch}$, 22-gauge spinal needle was inserted at the $\mathrm{L}_{4-5}$ interspace. Free flow of cerebrospinal fluid was obtained and $1.2 \mathrm{~mL}$ of $0.5 \%$ bupivacaine $(0.5 \mathrm{mg} / \mathrm{kg})$ with epinephrine $1: 200,000$ and clonidine $(1 \mu \mathrm{g} / \mathrm{kg}$ ) was injected through the spinal needle. The patient was positioned supine and a 22-gauge peripheral intravenous catheter was placed in the right foot. Prior to surgical incision, the adequacy of the spinal blockade was confirmed by motor blockade of the lower extremities and absence of response to skin prick. During the procedure, the patient breathed room air with a pacifier dipped in $24 \%$ sucrose solution in place. The oxygen saturation ranged from $80 \%$ to $85 \%$. Due to slight irritability, a single dose of dexmedetomidine $(0.5 \mu \mathrm{g} / \mathrm{kg})$ was administered intravenously prior to the start of procedure. The patient's heart rate prior to spinal anesthesia was 160 beats/ min with a blood pressure of $100-110 / 60-80 \mathrm{~mm} \mathrm{Hg}$. After spinal anesthesia, the heart rate decreased to a nadir of 80 beats/min and the blood pressure ranged from 80 - 100/40 - 50 $\mathrm{mm} \mathrm{Hg}$. The patient tolerated the 30 -min procedure without incident and was transferred to the post-anesthesia care unit. After meeting discharge criteria, he was discharged to home on the day of surgery.

\section{Discussion}

HLHS is a complex CHD characterized by abnormal development of left-sided cardiac structures, leading to inadequate systemic perfusion following post-natal closure of the patent ductus arteriosus (PDA) [16]. Surgical management of HLHS has traditionally been approached with a Norwood procedure during the neonatal period $[16,17]$. This involves extensive reconstruction of the aortic arch, thereby connecting the right ventricle with the systemic circulation and placement of a shunt to provide pulmonary blood flow. A more recent approach is the hybrid procedure, which combines interventional catheterbased stenting of the PDA to maintain systemic output, balloon atrial septostomy, and surgically placed pulmonary artery bands to limit pulmonary blood flow [15]. The hybrid approach defers aortic arch reconstruction with the need for cardiopulmonary bypass until the stage II procedure, when the patient is 4 - 8 months of age $[15,18]$. The proposed advantages of this strategy include improved hemodynamic stability after stage I and reduction in risk of brain and myocardial injury by avoiding cardiopulmonary bypass and aortic arch reconstruction in the early neonatal period.

Infants with HLHS frequently have associated conditions requiring non-cardiac surgical procedures. Given the associated co-morbid CHD, there is an increased risk of perioperative morbidity and mortality in this patient population [19]. In general, elective surgery should be carefully considered in such a patient, and a well-informed discussion between the surgeon, anesthesiologist, and parents should occur prior to proceeding. Despite such discussions, as was the case with our patient, families may still request surgical intervention.

In an effort to avoid the potential deleterious effects of general anesthesia, airway instrumentation, and the potential need for positive pressure ventilation, spinal anesthesia was chosen for our patient. Although first reported in a pediatric patient as early as 1899 , spinal anesthesia never gained significant popularity in pediatric anesthesia, being used in the 1980 s as a means of avoiding apnea following halothane anesthesia. Spinal anesthesia is currently seeing a resurgence as an alternative to general anesthesia, as it may limit the potential deleterious long-term neurocognitive effects of inhalational and intravenous anesthetic agents $[12,20]$.

Following the comprehensive stage II procedure on the hybrid pathway for patients with HLHS, the perioperative concerns include maintaining adequate pulmonary blood flow through the Glenn anastomosis. As pulmonary blood flow is passive, this is accomplished by maintaining adequate preload, avoiding increases in pulmonary vascular resistance, and limiting the use of medications with negative inotropic effects. Avoidance of prolonged NPO times, intravenous hydration while NPO, and fluid loading prior to anesthetic induction may be helpful in avoiding intravascular volume depletion. Endotracheal intubation, positive pressure ventilation, and the use of positive end expiratory pressure may all decrease pulmonary blood flow and cardiac output in this setting [21]. In our patient, we chose to use spinal anesthesia as a means of providing surgical anesthesia while avoiding the need for endotracheal intubation, positive pressure ventilation, and the use of intravenous and inhalational anesthetic agents with potentially negative inotropic effects.

The obvious concern regarding the use of spinal anesthesia in this scenario is the potential for adverse effects on hemodynamic function. However, spinal anesthesia (even high blockade) has been shown to have limited effects on hemodynamic function in infants and children less than 6 years of age [22]. Even deliberate high spinal anesthesia used for repair of PDA in neonates produced only a mild decline in blood pressure [23]. Unlike the adult population, sympathetic blockade with hypotension rarely occurs. This has traditionally been attributed to the incomplete development of the sympathetic nervous system in infants [24]. However, analysis of heart rate variability during the administration of spinal anesthesia in infants suggests that the reflex response to high spinal anesthesia is primarily due to diminished parasympathetic tone that offsets the blockade of sympathetic function [25]. This has been supported by clinical studies of spinal anesthesia in infants demonstrating that only a small percentage of patients required 
Table 1. Previous Reports of Spinal Anesthesia in Infants With Congenital Heart Disease

\begin{tabular}{|c|c|}
\hline $\begin{array}{l}\text { Authors and } \\
\text { reference }\end{array}$ & Study design and cohort \\
\hline $\begin{array}{l}\text { Peterson } \\
\text { et al }[28]\end{array}$ & $\begin{array}{l}\text { Retrospective review of regional anesthesia combined } \\
\text { with GA in } 220 \text { patients over a } 4 \text {-year period. }\end{array}$ \\
\hline $\begin{array}{l}\text { Hammer et } \\
\text { al }[29,30]\end{array}$ & $\begin{array}{l}\text { Retrospective review of } 50 \text { consecutive cases: } 25 \text { with } \\
\text { epidural and } 25 \text { with SA combined with GA. }\end{array}$ \\
\hline $\begin{array}{l}\text { Sacrista et } \\
\text { al [31] }\end{array}$ & $\begin{array}{l}\text { Case report of a } 38 \text {-week gestation, } 2,880 \mathrm{~g} \text { infant with } \\
\text { HLHS and anorectal atresia for colostomy under SA. }\end{array}$ \\
\hline $\begin{array}{l}\text { Finkel et } \\
\text { al [32] }\end{array}$ & $\begin{array}{l}\text { During GA with isoflurane, } 30 \text { patients }(7 \text { months to } 13 \\
\text { years) with CHD received SA with hyperbaric tetracaine } \\
\text { and morphine. Cephalad spread was promoted by } 30^{\circ} \\
\text { Trendelenburg positioning. }\end{array}$ \\
\hline $\begin{array}{l}\text { Katznelson } \\
\text { et al [33] }\end{array}$ & $\begin{array}{l}\text { Cohort study of } 12 \text { infants less than } 6 \text { months of age } \\
\text { undergoing diagnostic cardiac catheterization under SA } \\
\text { with } 1 \mathrm{mg} / \mathrm{kg} \text { of } 0.5 \% \text { bupivacaine. }\end{array}$ \\
\hline
\end{tabular}

Tobias [34] Case report of a 3-week-old, $3.6 \mathrm{~kg}$ infant with BlalockTaussig shunt palliation of $\mathrm{CDH}$, undergoing combined GA and SA for anorectoplasty.

Kachko et Retrospective review and comparison of 84 infants (42 al [35] with CHD and 42 without) undergoing non-cardiac surgery using SA (0.5 - $1 \mathrm{mg} / \mathrm{kg}$ of $0.5 \%$ bupivacaine).

Shenkman Retrospective review of 43 infants with non-cyanotic et al [36] CHD for inguinal herniorrhaphy under SA with $1 \mathrm{mg} / \mathrm{kg}$ of tetracaine or bupivacaine.

Williams Retrospective review of 14 patients undergoing surgical et al [23] closure of patent ductus arteriosus under deliberate high SA (tetracaine $2.4 \mathrm{mg} / \mathrm{kg}$ ) with mechanical ventilation.

\section{Outcomes}

Tracheal extubation in $89 \%$ in the operating room. $95 \%$ had pain scores $\leq 4.0$ at all postoperative intervals. Adverse effects included emesis (39\%), pruritus (10\%), urinary retention $(7 \%)$, transient paresthesia (3\%), and respiratory depression $(1.8 \%)$. The incidence of hematoma was 0 . The adverse effect rate was lower in thoracic epidural approach compared or others (caudal, lumbar epidural, spinal). Duration of stay was not affected.

No significant hemodynamic changes were noted.

Postoperative analgesia effects of the technique were reported in a subsequent publication.

SA with $0.8 \mathrm{~mL}$ of $0.5 \%$ isobaric bupivacaine instead of GA. No significant hemodynamic changes were noted.

No significant hemodynamic changes were noted. Although not specifically studied, intraoperative maintenance requirements for isoflurane were low (0.5-1\%).

No significant changes in hemodynamic or respiratory variables comparing perioperative vitals. Six patients required additional sedation with midazolam or ketamine. Discharge time was $33 \pm 12$ minutes.

Sevoflurane GA combined with SA (tetracaine and morphine). No significant hemodynamic changes were noted.

No between-group differences in MAP and heart rate changes after SA. Mild decrease in MAP from baseline of $20 \%$. Apnea without desaturation occurred in 1 patient.

No clinically significant hemodynamic changes. One patient was converted to GA due to the length of the procedure, two required supplemental oxygen.

Two patients had inadequate spinal level and received isoflurane. Half received no supplementation. Average maximal decrease in MAP was $7.8 \mathrm{~mm} \mathrm{Hg}$ with one patient having a decrease of 20 $\mathrm{mm} \mathrm{Hg}$ and a heart rate decrease to 125 from 180 beats/min, responsive to fluid and atropine treatment.

HLHS: hypoplastic left heart syndrome; CHD: congenital heart disease; GA: general anesthesia; MAP: mean arterial pressure; SA: spinal anesthesia.

treatment with intravenous fluids [26]. In our patient, no clinically significant changes in blood pressure or oxygen saturation were noted after the administration of spinal anesthesia. The decrease in heart rate to 80 beats/min was likely from the administration of intravenous dexmedetomidine to provide sedation [27]. Despite these data, the potential for hemodynamic changes should always be considered and appropriate monitoring be employed with ready access to resuscitation medications if needed. The potential safety of this approach is further supported by observational studies reporting no clinically significant reduction in blood pressure or oxygen saturation in high-risk infants with CHD during spinal anesthesia (Table 1) [28-36]. In these studies in infants and children with CHD, spinal anesthesia provided stable hemodynamic parameters without excessive hypotension requiring the administration of fluid or inotropic agents.
With the increasing use of spinal anesthesia in pediatric anesthesia, there have been several detailed reviews highlighting the important aspects of this technique $[20,37,38]$. In the neonate or infant, the sitting position is generally preferred for spinal anesthesia. The head should be slightly extended to avoid airway obstruction. Superficial analgesia with a topical local anesthetic cream is recommended to prevent pain during needle insertion. While we prefer to avoid the use of sedative agents, other investigators have suggested the administration of midazolam or ketamine to provide sedation during performance of the procedure [38]. At our institution, we prefer a non-pharmacological approach with a pacifier dipped in $24 \%$ sucrose oral solution whenever possible. Furthermore, we generally place the intravenous cannula in the foot after spinal anesthesia has been initiated. In our practice, a 1.5”, 22-gauge spinal needle with a stylet is used. After the epidermis and dermis are punc- 
tured, the stylet is removed as there may be only a subtle pop as the intrathecal space is entered. Once free flow of cerebrospinal fluid is obtained, the local anesthetic solution is injected. We generally aspirate only at the end of injection to clear the hub of the needle of remaining local anesthetic solution. The two commonly used local anesthetic agents are tetracaine or bupivacaine, with dose ranges from 0.4 to $1 \mathrm{mg} / \mathrm{kg}$. Higher intrathecal local anesthetic requirements in infants result from the larger per-kilogram volume of CSF compared to adults and proportionally greater blood flow leading to faster drug uptake. Although hyperbaric tetracaine solutions were previously used most commonly, many institutions, including ours, currently use isobaric bupivacaine $0.5 \%$. These dosing regimens will provide approximately $90 \mathrm{~min}$ of surgical anesthesia depending on the dermatomes involved [39]. The addition of epinephrine or clonidine may be used to prolong the duration of surgical anesthesia [40]. After performing the spinal, the infant is placed in the supine position with care taken not to raise the legs above the body to avoid unintentional high block. Though this should not be required with isobaric solutions, we nonetheless observe this precaution as an added safety measure.

Absolute contraindications to spinal anesthesia include parental refusal, history of true allergy to the local anesthetic agent, ongoing systemic infection with bacteremia, clinically significant coagulation disturbances, and intracranial hypertension or hemorrhage. Reports in the literature have demonstrated a very low incidence of significant adverse effects with spinal anesthesia in neonates and infants. The relatively high failure rate of spinal anesthesia reported in the literature highlights the importance of developing a robust spinal anesthesia program to optimize successful outcomes for awake spinal anesthesia in these high-risk infants [14]. With these caveats in mind, spinal anesthesia should be considered a safe and effective alternative to general anesthesia in high-risk neonates and infants, especially those with co-morbid CHD. We also recommend effective communication between providers as well as the family to enhance the safety of this approach. This should include a well-informed discussion with the family and then physician-to-physician consultation to ensure proper preparation for such cases.

\section{References}

1. Abajian JC, Mellish RW, Browne AF, Perkins FM, Lambert DH, Mazuzan JE, Jr. Spinal anesthesia for surgery in the high-risk infant. Anesth Analg. 1984;63(3):359-362.

2. Sartorelli KH, Abajian JC, Kreutz JM, Vane DW. Improved outcome utilizing spinal anesthesia in high-risk infants. J Pediatr Surg. 1992;27(8):1022-1025.

3. Veverka TJ, Henry DN, Milroy MJ, Snyder ME, Fabian E, Groch JA, Cobb LM. Spinal anesthesia reduces the hazard of apnea in high-risk infants. Am Surg. 1991;57(8):531534; discussion 534-535.

4. Harnik EV, Hoy GR, Potolicchio S, Stewart DR, Siegelman RE. Spinal anesthesia in premature infants recovering from respiratory distress syndrome. Anesthesiology. 1986;64(1):95-99.

5. Webster AC, McKishnie JD, Kenyon CF, Marshall DG.
Spinal anaesthesia for inguinal hernia repair in high-risk neonates. Can J Anaesth. 1991;38(3):281-286.

6. Blaise GA, Roy WL. Spinal anaesthesia for minor paediatric surgery. Can Anaesth Soc J. 1986;33(2):227-230.

7. Welborn LG, Rice LJ, Hannallah RS, Broadman LM, Ruttimann UE, Fink R. Postoperative apnea in former preterm infants: prospective comparison of spinal and general anesthesia. Anesthesiology. 1990;72(5):838-842.

8. Sale SM, Read JA, Stoddart PA, Wolf AR. Prospective comparison of sevoflurane and desflurane in formerly premature infants undergoing inguinal herniotomy. Br J Anaesth. 2006;96(6):774-778.

9. William JM, Stoddart PA, Williams SA, Wolf AR. Postoperative recovery after inguinal herniotomy in ex-premature infants: comparison between sevoflurane and spinal anaesthesia. Br J Anaesth. 2001;86(3):366-371.

10. Davidson AJ. Anesthesia and neurotoxicity to the developing brain: the clinical relevance. Paediatr Anaesth. 2011;21(7):716-721.

11. McGowan FX, Jr., Davis PJ. Anesthetic-related neurotoxicity in the developing infant: of mice, rats, monkeys and, possibly, humans. Anesth Analg. 2008;106(6):15991602.

12. Blaylock M, Engelhardt T, Bissonnette B. Fundamentals of neuronal apoptosis relevant to pediatric anesthesia. Paediatr Anaesth. 2010;20(5):383-395.

13. Davidson AJ, Morton NS, Arnup SJ, de Graaff JC, Disma N, Withington DE, Frawley G, et al. Apnea after Awake Regional and General Anesthesia in Infants: The General Anesthesia Compared to Spinal Anesthesia Study - Comparing Apnea and Neurodevelopmental Outcomes, a Randomized Controlled Trial. Anesthesiology. 2015;123(1):38-54.

14. Frawley G, Bell G, Disma N, Withington DE, de Graaff JC, Morton NS, McCann ME, et al. Predictors of Failure of Awake Regional Anesthesia for Neonatal Hernia Repair: Data from the General Anesthesia Compared to Spinal Anesthesia Study - Comparing Apnea and Neurodevelopmental Outcomes. Anesthesiology. 2015;123(1):55-65.

15. Galantowicz M, Cheatham JP, Phillips A, Cua CL, Hoffman TM, Hill SL, Rodeman R. Hybrid approach for hypoplastic left heart syndrome: intermediate results after the learning curve. Ann Thorac Surg. 2008;85(6):20632070; discussion 2070-2061.

16. Grossfeld PD. Hypoplastic left heart syndrome: it is all in the genes. J Am Coll Cardiol. 2007;50(16):1596-1597.

17. Grotenhuis HB, Ruijsink B, Chetan D, Dragulescu A, Friedberg MK, Kotani Y, Caldarone CA, et al. Impact of Norwood versus hybrid palliation on cardiac size and function in hypoplastic left heart syndrome. Heart. 2016;102(12):966-974.

18. Galantowicz M, Yates AR. Improved outcomes with the comprehensive stage 2 procedure after an initial hybrid stage 1. J Thorac Cardiovasc Surg. 2016;151(2):424-429.

19. Ramamoorthy C, Haberkern CM, Bhananker SM, Domino KB, Posner KL, Campos JS, Morray JP. Anesthesiarelated cardiac arrest in children with heart disease: data from the Pediatric Perioperative Cardiac Arrest (POCA) registry. Anesth Analg. 2010;110(5):1376-1382. 
20. Tobias JD. Spinal anaesthesia in infants and children. Paediatr Anaesth. 2000;10(1):5-16.

21. Rimensberger PC, Heulitt MJ, Meliones J, Pons M, Bronicki RA. Mechanical ventilation in the pediatric cardiac intensive care unit: the essentials. World J Pediatr Congenit Heart Surg. 2011;2(4):609-619.

22. Dohi S, Naito H, Takahashi T. Age-related changes in blood pressure and duration of motor block in spinal anesthesia. Anesthesiology. 1979;50(4):319-323.

23. Williams RK, Abajian JC. High spinal anaesthesia for repair of patent ductus arteriosus in neonates. Paediatr Anaesth. 1997;7(3):205-209.

24. Oberlander TF, Berde CB, Lam KH, Rappaport LA, Saul JP. Infants tolerate spinal anesthesia with minimal overall autonomic changes: analysis of heart rate variability in former premature infants undergoing hernia repair. Anesth Analg. 1995;80(1):20-27.

25. Assali NS, Brinkman CR, 3rd, Woods JR, Jr., Dandavino A, Nuwayhid B. Development of neurohumoral control of fetal, neonatal, and adult cardiovascular functions. Am J Obstet Gynecol. 1977;129(7):748-759.

26. Mahe V, Ecoffey C. Spinal anesthesia with isobaric bupivacaine in infants. Anesthesiology. 1988;68(4):601-603.

27. Tobias JD, Gupta P, Naguib A, Yates AR. Dexmedetomidine: applications for the pediatric patient with congenital heart disease. Pediatr Cardiol. 2011;32(8):1075-1087.

28. Peterson KL, DeCampli WM, Pike NA, Robbins RC, Reitz BA. A report of two hundred twenty cases of regional anesthesia in pediatric cardiac surgery. Anesth Analg. 2000;90(5):1014-1019.

29. Hammer GB, Ngo K, Macario A. A retrospective examination of regional plus general anesthesia in children undergoing open heart surgery. Anesth Analg. 2000;90(5):1020-1024.

30. Hammer GB, Ramamoorthy C, Cao H, Williams GD, Boltz MG, Kamra K, Drover DR. Postoperative analgesia after spinal blockade in infants and children undergoing cardiac surgery. Anesth Analg. 2005;100(5):1283-1288, table of contents.

31. Sacrista S, Kern D, Fourcade O, Izard P, Galinier P, Samii $\mathrm{K}$, Cathala B. Spinal anaesthesia in a child with hypoplastic left heart syndrome. Paediatr Anaesth. 2003;13(3):253256.

32. Finkel JC, Boltz MG, Conran AM. Haemodynamic changes during high spinal anaesthesia in children having open heart surgery. Paediatr Anaesth. 2003;13(1):48-52.

33. Katznelson R, Mishaly D, Hegesh T, Perel A, Keidan I. Spinal anesthesia for diagnostic cardiac catheterization in high-risk infants. Paediatr Anaesth. 2005;15(1):50-53.

34. Tobias JD. Combined general and spinal anesthesia in an infant with single-ventricle physiology undergoing anorectoplasty for an imperforate anus. J Cardiothorac Vasc Anesth. 2007;21(6):873-875.

35. Kachko L, Birk E, Simhi E, Tzeitlin E, Freud E, Katz J. Spinal anesthesia for noncardiac surgery in infants with congenital heart diseases. Paediatr Anaesth. 2012;22(7):647-653.

36. Shenkman Z, Johnson VM, Zurakowski D, Arnon S, Sethna NF. Hemodynamic changes during spinal anesthesia in premature infants with congenital heart disease undergoing inguinal hernia correction. Paediatr Anaesth. 2012;22(9):865-870.

37. Lederhaas G. Spinal anaesthesia in paediatrics. Best Pract Res Clin Anaesthesiol. 2003;17(3):365-376.

38. Lopez T, Sanchez FJ, Garzon JC, Muriel C. Spinal anesthesia in pediatric patients. Minerva Anestesiol. 2012;78(1):78-87.

39. Rice LJ, DeMars PD, Whalen TV, Crooms JC, Parkinson SK. Duration of spinal anesthesia in infants less than one year of age. Comparison of three hyperbaric techniques. Reg Anesth. 1994;19(5):325-329.

40. Rochette A, Troncin R, Raux O, Dadure C, Lubrano JF, Barbotte E, Capdevila X. Clonidine added to bupivacaine in neonatal spinal anesthesia: a prospective comparison in 124 preterm and term infants. Paediatr Anaesth. 2005;15(12):1072-1077. 